\title{
TSUNAMI CASUALTY ESTIMATION CONSIDERING INTENDED EVACUATION BEHAVIOR OF LOCAL RESIDENTS AND VISITORS
}

\author{
Tomoyuki Takabatake, Waseda University, tomoyuki.taka.8821@gmail.com \\ Tomoya Shibayama, Waseda University, shibayama@waseda.jp \\ Esteban Miguel, Waseda University, esteban.fagan@gmail.com
}

\begin{abstract}
INTRODUCTION
Tsunamis could cause devastating damage to vast coastal areas. In order to understand tsunami hazards in a certain area, it is important to assess the potential casualties that can result from a given event. Although many studies related to tsunami casualty estimations exist, most of them have not taken detailed evacuation behavior of at-risk individuals into account. For instance, although people have been found to have a variety of triggers that can prompt them to evacuate (e.g. feeling earthquake shaking, seeing others evacuating), to the authors' knowledge these effects have been ignored when conducting an estimation of the numbers of potential casualties. For some coastal areas, during a tsunami large number of visitors could be present, who have less knowledge about the locations of safe places. Nevertheless, there has also been little consideration regarding their presence and behavior. In this study, an advanced approach for estimating the number of tsunami casualties is presented and applied to Yuigahama Beach, Kamakura City, Japan, which has a high risk of tsunami and large number of tourists throughout the whole year.
\end{abstract}

\section{METHODOLOGY}

The approach presented in this study is based on Takabatake et al. (2018), and uses an agent-based tsunami evacuation simulation model that considers a variety of types of evacuation behavior of local resident and visitors. Behavior parameters are incorporated using the results from previous questionnaire surveys, which had investigated tsunami awareness and intended evacuation behavior of local residents and visitors (e.g. Carlos-Arce et al. 2017). For instance, the evacuation start time is defined based on the questionnaire results regarding evacuation triggers and the time it will take people to start actual evacuation. It is assumed that when a trigger event (4 types of triggers were considered, namely "Ground shaking (hereafter, denoted as T1)", "Tsunami warning (T2)", "See others evacuating (T3)", and "See the tsunami (T4)") occurs, the agents assigned to that trigger will decide to evacuate, and after a preparation time has passed they will start doing so. The choice of evacuation route for each agent is also defined based on the results of the questionnaire surveys. For instance, route choice of visitor agents who do not know the area well is set to go to higher ground or follow other individuals. The casualty numbers are calculated using the results of a tsunami inundation simulation, which is based on the nonlinear long wave equations. The agents are assumed to perish if the simulated depth-velocity product $(D V)$ at their location exceeds their stability limit.

\section{RESULTS}

Figure 1 shows a snapshot of the casualty estimation simulation. When the tsunami wave reached the agents and the value of $D V$ exceeded the agent's stability limit, the agents became casualties. Figure 2 shows the results of tsunami casualty estimation. Total number of casualties were estimated to be over 1,500 , and many of them were

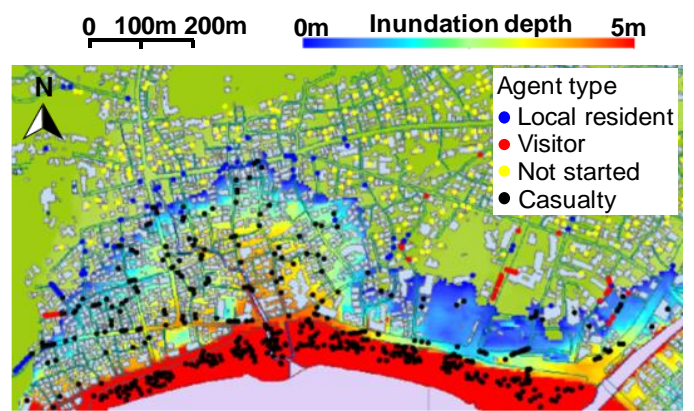

Fig.1 Snapshot of the casualty estimation
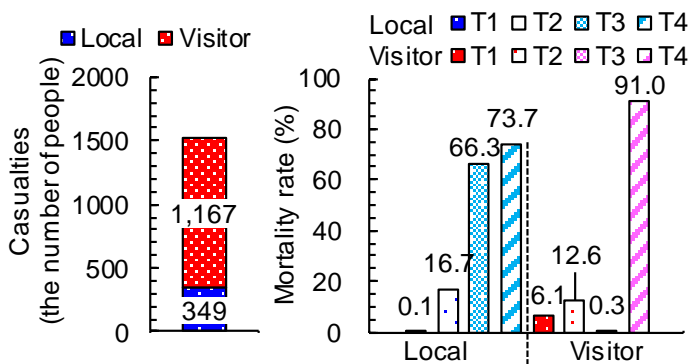

(a) Casualty number

(b) Mortality rates

Fig.2 Results of the casualty estimation

found to be visitors, indicating that this group is more vulnerable to tsunamis (see Fig.2(a)). Fig.2(b) shows the mortality rates summarized in terms of the evacuation triggers. Most agents who started their evacuation after feeling ground shaking (T1) or hearing tsunami warnings (T2) survived, and most T4 agents died. Based on the results, it would be important for the authorities to inform these people of the risks of such action and to change their intended evacuation behavior. The results also showed that visitors who know the closest evacuation places were more likely to survive than those going to higher ground or following other agents.

\section{CONCLUSIONS}

An advanced approach to estimate the number of tsunami casualties was developed, which considers a variety of tsunami awareness and intended evacuation behavior of both local residents and visitors, and provides more detailed information about tsunami risks and effective countermeasures. This methodology represents a significant improvement on previous studies, highlighting the need to incorporate real intended evacuation behavior questionnaires into evacuation simulations.

\section{REFERENCES}

Carlos-Arce et al. (2017): Risk awareness and intended tsunami evacuation behaviour of international tourists in Kamakura City, Japan, International Journal of Disaster Risk Reduction, ELSEVIER, vol. 23, pp. 178-192.

Takabatake et al. (2018): Advanced casualty estimations based on tsunami evacuation intended behavior: Case study at Yuigahama Beach, Kamakura, Japan, Natural Hazards, 1-26. [doi:10.1007/s11069-018-3277-0] 